\title{
Balaio de Gatos: A formação leitora de crianças de 2 e 3 anos
}

\author{
Alessandra Izabel dos Santos Lourenço \\ UNITAU - Universidade de Taubaté
}

\begin{abstract}
Resumo
O presente artigo traz o relato de experiência da realização do projeto Balaio de Gatos realizado com turma do infantil 1, com crianças de 2 e 3 anos. A turma ao se comunicar, utilizava um vocabulário bem restrito dando preferência a gestos quando desejavam algo. Os objetivos deste trabalho foram auxiliar na ampliação do vocabulário e na desenvoltura da fala por meio do reconto da história Era uma vez um gato xadrez, de Bia Villela (2003), e despertar o gosto pela literatura, contribuindo com a formação de leitores. Para tanto, utilizaremos como fundamentação teórica as concepções de Oliveira (1997), sobre a aquisição da linguagem e Cademartori (2014), sobre a importância da literatura na formação da linguagem. Conclui-se que a literatura, por seus encantos e fascínios, propicia aos alunos o enriquecimento do vocabulário, colaborando com a desenvoltura da fala e com a formação leitora.
\end{abstract}

Palavras-chave: Literatura. Desenvolvimento da fala. Formação de leitor.

\begin{abstract}
This article reports on the experience of the Balaio de Gatos project carried out with children's group 1, in the age group of 2 and 3 years old. The class would communicate through a very restricted vocabulary, preferring to use gestures when they wanted something. The objectives of this work were to contribute to the expansion of vocabulary and the development of speaking through the retelling of the story "Once upon a time a chess cat," by Bia Villela (2013), and to awaken the taste for literature, thus contributing reader development. The theoretical basis was Oliveira (1997) concerning the acquisition of language, and Cademartori (2014) concerning literature in the formation of language. It can be concluded that, because of its charms and fascinations, literature provides students with the enrichment of vocabulary, collaborating with the ease of speech and with reader development.
\end{abstract}

Keywords: Literature. Speech development. Reader development

\section{INTRODUÇÃo}

As crianças de dois e três anos estão desenvolvendo a linguagem oral, aprendendo novas palavras e as incorporando ao seu vocabulário. Este artigo relata a experiência do Projeto Balaio de Gatos, realizado com uma turma da Educação Infantil de dois e três anos que apresentavam um vocabulário bem restrito, precisando de estímulos para se apropriar de novas palavras. 
Os objetivos deste trabalho foram: contribuir com a ampliação do vocabulário e com a desenvoltura da fala por meio do reconto da história Era uma vez um gato xadrez, de Bia Villela (2003), despertar o gosto pela literatura como fonte de prazer e entretenimento e contribuir com a formação de leitores.

Para tanto, uma sequência de atividades com o livro Era uma vez um gato xadrez, (BIA VILLELA, 2003), foi elaborada e desenvolvida durante o segundo semestre de 2016 em uma escola de Educação Infantil federal, dentro do DCTA, em São José dos Campos, SP.

Espera-se que esta pesquisa possa contribuir com professores que prezam por ensinar proporcionando prazer e entretenimento às crianças pequenas, considerando que "[...] o despertar da inteligência e o da imaginação caminham juntos e constantemente se enriquecem" (HELD, 1980, p.48).

Para embasar o desenvolvimento do tema, foram buscadas importantes contribuições de Oliveira (1997), por esclarecer sobre a aquisição da linguagem, Cademartori (2014) por elucidar sobre a literatura na formação da linguagem e Candido (1995) por enfatizar a importância da literatura na formação humana.

Conclui-se que a literatura, por seus encantos e fascínios, propicia o enriquecimento do vocabulário, colaborando com a desenvoltura da fala e contribuindo com a formação leitora.

Nas próximas seções, apresento a fundamentação teórica, o percurso metodológico e as considerações acerca dos resultados obtidos.

\section{FUNDAMENTAÇÂO TEÓRICA}

A criança de 2 e 3 anos, conforme explica Martinez (2014), apresenta grande avanço na linguagem oral e na compreensão do mundo. É nessa fase que a brincadeira com as palavras e a memorização de rimas tornam-se mais frequentes, A criança começa a identificar-se e a envolver-se afetivamente com o livro, aumentando o tempo que consegue prestar atenção em uma história.

$\mathrm{Na}$ concepção vygotskyana, por volta dos dois anos de idade, as trajetórias do pensamento e da linguagem se fundem, dando origem ao pensamento e à linguagem de forma racional, "a fala torna-se intelectual, com função simbólica, generalizante, e o pensamento torna-se verbal, mediado por significados dados pela linguagem" (OLIVEIRA, 1997, p. 47). Embora cada criança percorra um caminho próprio de 
desenvolvimento da fala, a interação verbal com seus colegas e adultos, como professores, pais e agentes educadores, proporciona a ampliação do vocabulário e o avanço na compreensão dos significados das palavras.

Embora o desenvolvimento da fala aconteça de forma peculiar e em um ritmo próprio para cada uma, o Referencial Curricular Nacional para a Educação Infantil (1998), esclarece que a "aprendizagem da fala pelas crianças não se dá de forma desarticulada com a reflexão, o pensamento, a explicitação de seus atos, sentimentos, sensações e desejos" (p. 125). O desenvolvimento acontece dentro de um contexto de interações e estímulos, mediado pelo adulto.

A leitura de histórias com rimas e o brincar com as palavras desencadeia em uma importante etapa de exploração das possibilidades da fala. Cademartori (2014) coloca que

[...] é preciso brincar com palavras. Lembrando José Paulo Paes: 'bola, papagaio, pião de tanto brincar se gastam. As palavras não. Quanto mais se brinca com elas, mais novas ficam' [...] a versificação, nessa etapa, se insere no mundo infantil como um jogo, continuidade do brinquedo com as unidades linguísticas (p. 36).

Para o momento de atividade com crianças, o professor precisa ler muitas histórias e proporcionar um momento de conversa sobre esses textos, conforme Cardoso e Sepúlveda (2014), pois desta forma, estará ajudando a criança a construir um repertório mais amplo e rico da língua materna. E, além de proporcionar momentos de prazer e entretenimento, traz a oportunidade de alavancar o desenvolvimento da competência linguística.

A criança que ouve a leitura em voz alta feita por um adulto e que depois tem a oportunidade de manusear o livro, explorando-o de forma lúdica, se familiariza "com a estrutura da língua" descobrindo "as possibilidades combinatórias da língua, suas potencialidades, seus recursos de expressão" (CADEMARTORI, 2014, p. 36).

O livro de histórias com jogo de palavras, traz representações ou rimas que encantam, divertem, instruem, ensinam e cativam. Huzinga (1971) explica que "O jogo lança sobre nós um feitiço: é 'fascinante', 'cativante'. Está cheio das duas qualidades mais nobres que somos capazes de ver nas coisas: o ritmo e a harmonia” (p. 3). A leitura dos livros infantis, seja qual for o gênero, proporciona em sua essência um jogo que encanta e diverte.

Quanto mais cedo as crianças tiverem acesso aos livros e à escuta de histórias, mais cedo irá desenvolver o hábito da leitura. Cademartori (2014) observa que o livro 
literário "pode oferecer às crianças, desde a mais tenra idade, o material simbólico inicial para que possam ir descobrindo não apenas quem elas são, mas também quem elas querem e podem ser" (p. 9).

A literatura é essencial para introduzir a criança no mundo simbólico. Held (1980) explica que “O 'Era uma vez' constitui o 'Abre-te Sésamo' de um universo de liberdade onde tudo pode acontecer" (p. 44). O mundo de fantasia, de representações convida a criança a alimentar sua imaginação, tornando-o prazeroso, instigando-a a se interessar em ouvir mais histórias.

Além de desenvolver as competências da língua materna e contribuir com a formação de leitor, a literatura é essencial também no desenvolvimento do processo de humanização e enriquecimento cultural. Candido (1995) sugere que a literatura nos torna mais humanos e comprometidos com a sociedade e com o semelhante porque tem o poder de sensibilizar as pessoas, despertando nelas as boas ações para com o próximo.

A literatura fornece o equilíbrio que precisamos para agir no mundo, a forma de encararmos os acontecimentos. Muitas coisas que são incompreensíveis passam a ser compreensíveis sob a luz da literatura e "pelo fato de dar forma aos sentimentos e à visão de mundo, ela nos organiza, nos liberta do caos e, portanto, nos humaniza" Candido (1995, p. 256).

Por meio da literatura podem ser trabalhados conteúdos de vários eixos ou disciplinas, servindo como um centro organizador, onde ao seu entorno, outros eixos, ou disciplinas, sejam interligados. Para Coelho (2000), o mundo se constitui na linguagem, desta forma, a literatura serviria como um fio condutor para atrelar conhecimentos, transformando o ensino em algo mais interessante e eficiente.

Na próxima seção serão apresentadas as etapas do trabalho com o livro Era uma vez um gato xadrez, de Bia Villela (2003), com o projeto Balaio de Gatos.

\section{PERCURSO METODOLÓGICO}

O livro Era uma vez um gato xadrez (BIA VILLELA, 2003) foi escolhido por ser composta por quadrinhas que, com suas rimas, pudesse agradar os alunos e servisse de mola propulsora para o desenvolvimento da linguagem oral e ampliação do vocabulário. 
Com esse livro idealizei o projeto Balaio de Gatos que teve duração de um semestre, trabalhado no eixo Linguagem Oral com quatro aulas semanais.

As atividades do projeto constaram das seguintes etapas:

\section{Apresentação do livro Era uma vez, um gato um xadrez, Bia Villela (2003):}

Figura 1

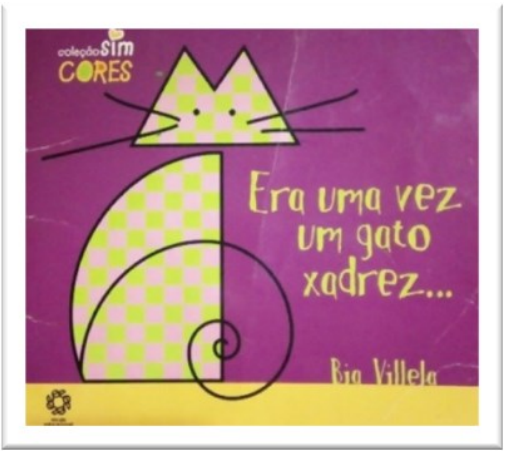

Fotocópia da capa original

Li o livro, página por página, passando-as devagar para que as crianças observassem melhor as imagens. As crianças prestaram muita atenção, divertindo-se com as rimas das quadrinhas.

Figura 2

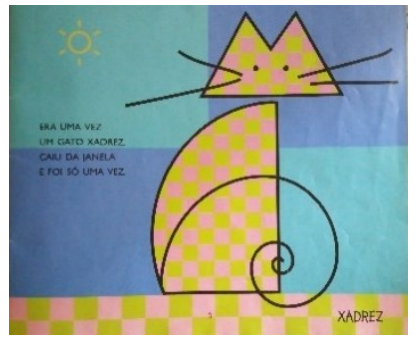

Transcrição do texto:

"ERA UMA VEZ

UM GATO XADREZ.

CAIU DA JANELA

Fotocópia da imagem original

E FOI SÓ UMA VEZ."

Figura 3

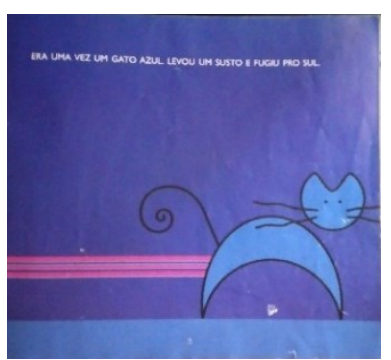

Transcrição do texto:

“ERA UMA VEZ

UM GATO AZUL.

LEVOU UM SUSTO

E FUGIU PRO SUL.”

Fotocópia da imagem original 
Figura 4

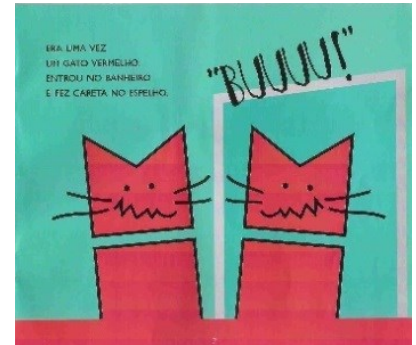

Fotocópia da imagem original

Figura 5

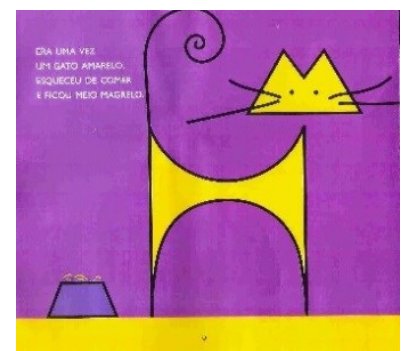

Fotocópia da imagem original

Figura 6

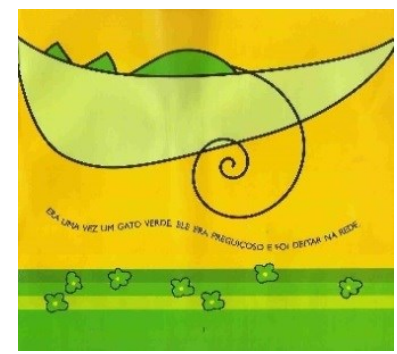

Fotocópia da imagem original

Figura 7

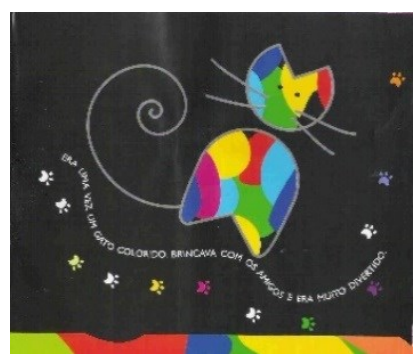

Fotocópia da imagem original
Transcrição do texto:

"ERA UMA VEZ

UM GATO VERMELHO.

ENTROU NO BANHEIRO

E FEZ CARETA NO ESPELHO."

Transcrição do texto:

"ERA UMA VEZ

UM GATO AMARELO.

ESQUECEU DE COMER

E FICOU MEIO MAGRELO.

Transcrição do texto:

"ERA UM AVEZ

UM GATO VERDE.

ELE ERA PREGUIÇOSO

E FOI DEITAR NA REDE.

Transcrição do texto:

"ERA UMA VEZ

UM GATO COLORIDO.

BRINCAVA COM OS AMIGOS

E ERA MUITO DIVERTIDO.” 
Figura 8

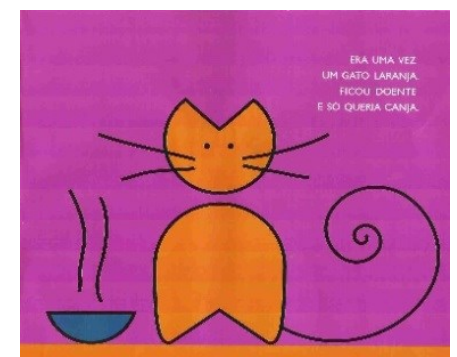

Fotocópia da imagem original

Figura 9

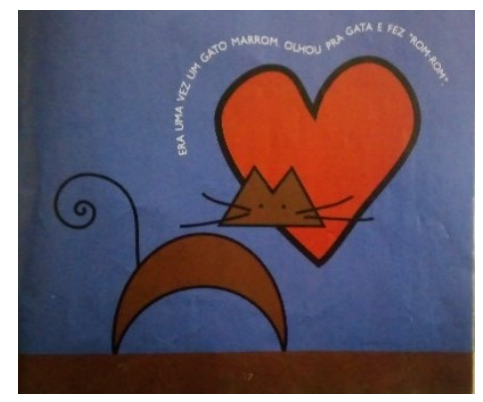

Fotocópia da imagem original

Figura 10

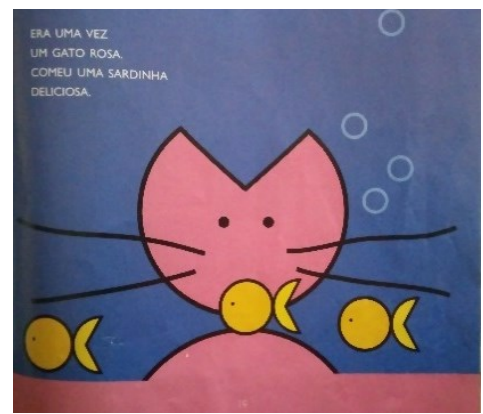

Fotocópia da imagem original

Figura 11

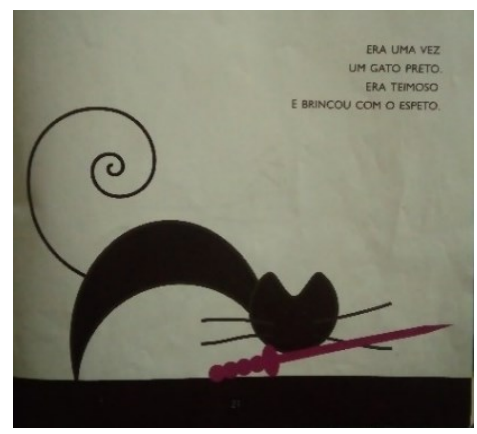

Fotocópia da imagem original
Transcrição do texto:

"ERA UMA VEZ

UM GATO LARANJA

FICOU DOENTE

E SÓ QUERIA CANJA."

Transcrição do texto:

"ERA UMA VEZ

UM GATO MARROM.

OLHOU PARA A GATA

E FEZ ROM-ROM.”

Transcrição do texto:

"ERA UMA VEZ

UM GATO ROSA.

COMEU UMA SARDINHA

DELICIOSA."

Transcrição do texto:

“ERA UMA VEZ

UM GATO PRETO.

ERA TEIMOSO

E BRINCOU COM O

ESPETO.” 
Figura 12

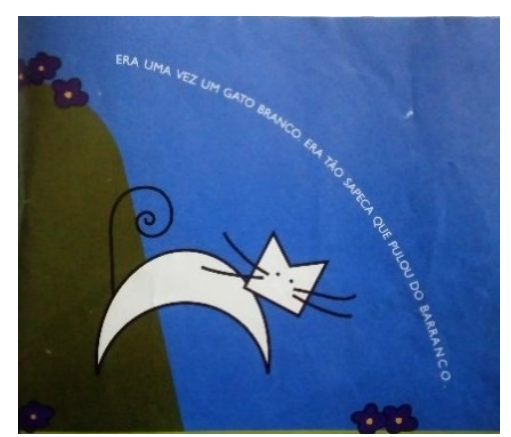

Transcrição do texto:

"ERA UMA VEZ

UM GATO BRANCO.

ERA TÃO SAPECA

QUE PULOU DO BARRANCO”

Fotocópia da imagem original

Figura 13

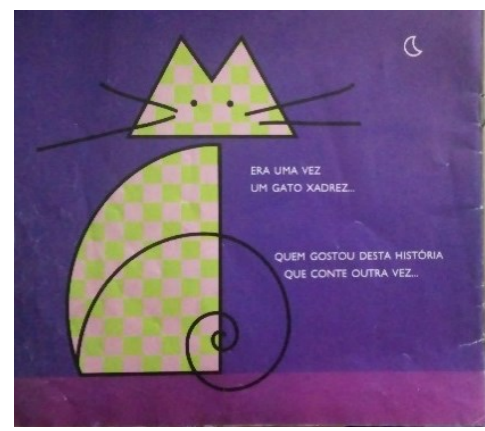

Fotocópia da imagem original
Transcrição do texto:

ERA UMA VEZ

UM GATO XADREZ.

QUEM GOSTOU DESTA

HISTÓRIA

QUE CONTE OUTRA VEZ...

\section{Apresentação da autora:}

Ao final do livro, perguntei às crianças: Quem será que escreveu essa história? Foi homem ou mulher? Algumas responderam que foi um homem e outros que foi uma mulher. Então respondi: - Vou ler o nome: Bia Villela! E os ouço repetindo baixinho: “- Tia Villela”. Mostrei a foto da autora e li a pequena biografia que consta no anverso da contracapa, explicando que ela também ilustrou a história, desenhando os gatos e os colorindo.

Figura 14

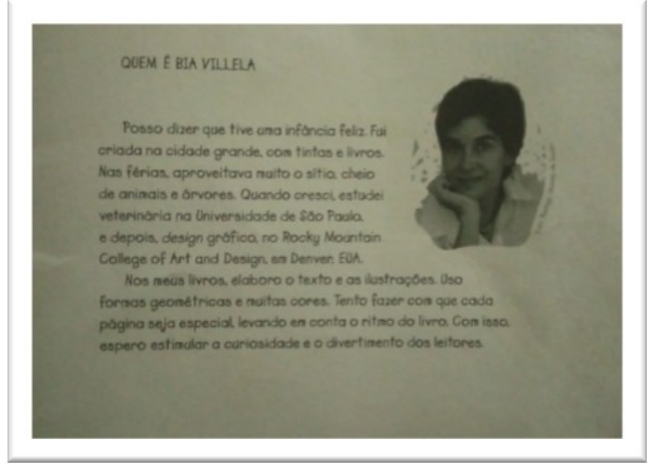

Fotocópia da imagem original 


\section{Leitura e reconto}

Depois das leituras feitas em quatro aulas, na quinta aula entreguei o livro às crianças para que manuseassem, recontando a história por meio da leitura de imagens. Combinamos que cada uma veria o livro e depois o passaria para o amigo. O prazer que a turma demonstrou durante as atividades de leitura e reconto fez com que repetíssemos a leitura muitas vezes em uma mesma aula.

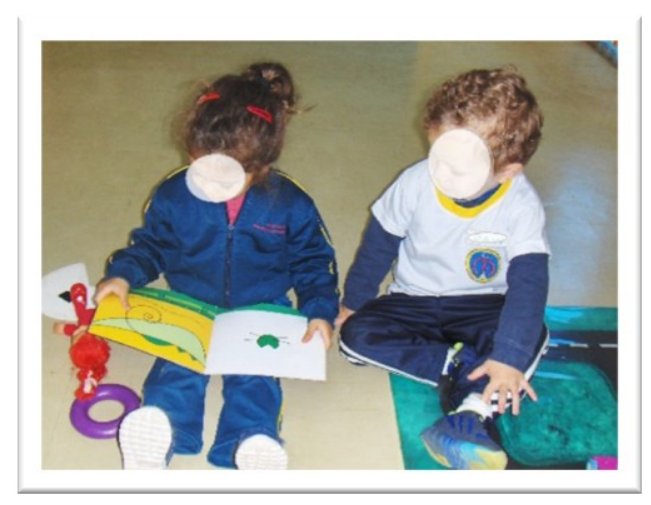

\section{Brincando de recitar}

As crianças passaram a recitar as quadrinhas que mais gostaram em muitos momentos do dia. Os pais me abordaram pelos corredores da escola, na hora da saída, me perguntando sobre a história do Gato Xadrez, querendo mais informações sobre o livro.

\section{Fantoches dos gatos}

Com papel cartão confeccionei a cara de cada gato, seguindo o formato que a autora utilizou para representá-los. Apresentei os fantoches, um a um, seguindo a sequência em que eles aparecem no livro. Conforme os fantoches eram apresentados, eu iniciava a frase e a turma completava a quadrinha. 


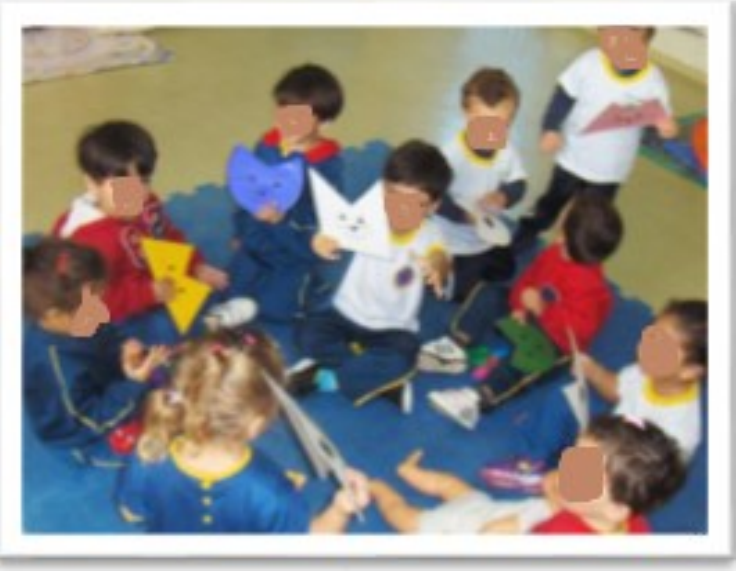

\section{Fichas com indícios}

Confeccionei fichas, com medidas de 40 por 50 centímetros, em papéis coloridos. Em cada ficha, reproduzi a ilustração de algum objeto da quadrinha para que servisse de indício. Por exemplo, para a quadrinha do gato verde, desenhei na ficha uma rede apenas. Para a ficha do gato rosa, desenhei uma sardinha. Foram confeccionadas doze fichas para os doze gatos. Em outra aula de Linguagem, fiz a leitura do livro e apresentei à turma a ficha que tinha o desenho da sardinha e perguntei: - Quem mora nesta casinha? As crianças me responderam que era o gato rosa que comeu uma sardinha deliciosa. Espalhei as fichas pelo chão, entreguei às crianças os fantoches dos gatos e orientei: - "Vocês vão ajudar cada gato a chegar na sua casinha; para isso, recitem a quadrinha para ajudá-los a lembrar a cor do gato, e coloquem o fantoche sobre a casinha onde ele mora”. (Usei a palavra casinha, referindo-me às fichas, para que a atividade acontecesse de forma lúdica e prazerosa). A turma se divertiu, pois, a atividade os desafiava a lembrar das cores de cada gato e qual o objeto que a autora fez para cada um deles.

\section{Cartazes}

Para o nosso mural externo confeccionamos um cartaz para cada semana com a quadrinha escolhida pela turma. Recortei a figura do gato para as crianças pintarem com tinta guache. Juntamente comigo, colaram o gato na cartolina e a quadrinha digitada e impressa previamente. 

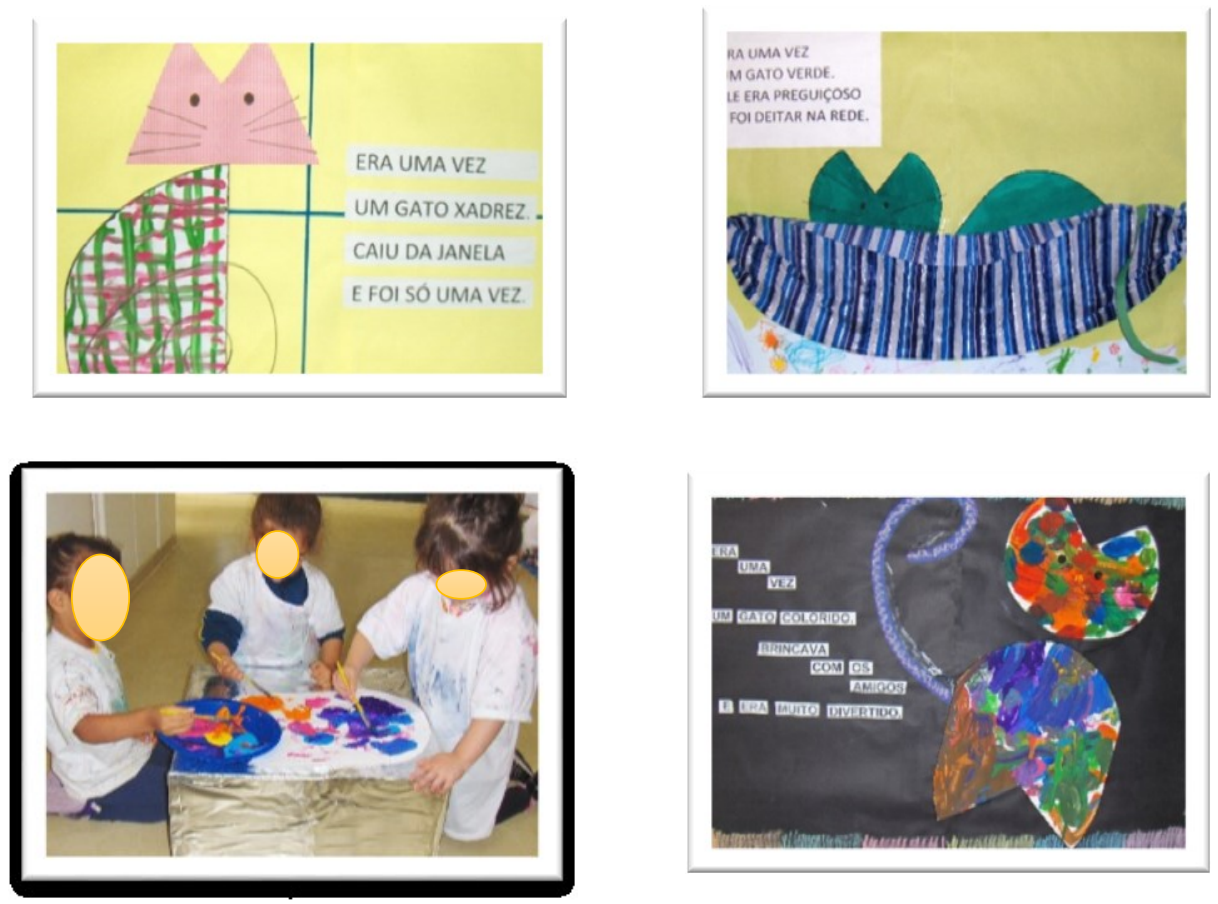

\section{Mostra no II Sarau da nossa escola: Finalização do Projeto}

Para finalizar as etapas, participamos da Mostra em nossa escola expondo o material que confeccionamos.

Os pais apreciaram a exposição, felizes com o nosso trabalho. Os pais das crianças de outras turmas queriam saber mais sobre as atividades. Ouvíamos as crianças pedindo para seus pais comprarem o livro do gato xadrez, fazendo referência ao livro Era uma vez um gato Xadrez, (Villela, 2003).

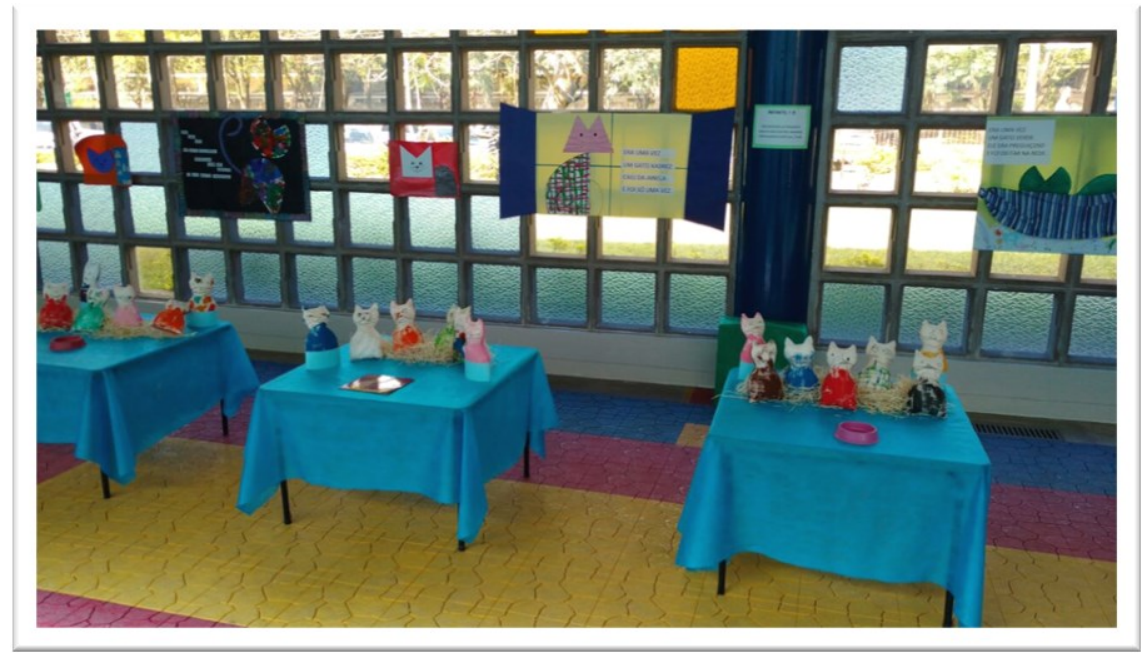




\section{RESULTADOS}

O trabalho com a sequência de atividades com o livro Era uma vez um gato $x a d r e z$, de Bia Villela (2003), encantou com suas rimas e ilustrações de cores vivas. Ao chegar pela manhã, as crianças pegavam o livro, os fantoches, as fichas e recitavam as quadrinhas memorizadas. $\mathrm{O}$ final do projeto culminou com o encerramento do semestre, porém, se dependesse das crianças ele continuaria por mais tempo.

Com as quadrinhas memorizadas, as crianças mais tímidas tiveram a segurança para se expressarem verbalmente. Um dos alunos, que não falava nada no início do projeto, apaixonou-se pelo livro e com ele em mãos foi capaz de recontar toda a história, fazendo o reconto para qualquer colega que se aproximava. Foi uma das nossas maiores conquistas. A família, antes preocupada querendo levá-lo ao fonoaudiólogo, no final, agradecia porque em casa ele queria ler o livro para todas as visitas.

Além de recitar as quadrinhas, a turma falava sobre seus animais de estimação, suas cores preferidas e sobre algum gato que haviam visto ao sair para algum passeio... E, assim, falavam com mais desenvoltura, com coerência, prestando atenção no que o colega estava dizendo.

No momento de escolherem um livro na biblioteca da sala, queriam histórias relacionadas a gatos. Com outros livros imaginavam outras histórias, fazendo a leitura de imagem e contando aos colegas as histórias recriadas por elas.

O projeto alcançou todos os objetivos propostos de uma forma prazerosa e enriquecedora.

Conclui-se, desta forma que a literatura, além de contribuir para a formação pessoal, proporcionar prazer e entretenimento, é uma estratégia eficiente para se trabalhar os conteúdos.

\section{REFERÊNCIAS}

BRASIL. Secretaria de Educação Fundamental. Referencial Nacional Curricular para a Educação Infantil. Brasília: MEC/SEF, 1998

CADEMARTORI, L. As narratividades. In: Seminário Internacional Literatura na Educação Infantil: acervos, espaços e mediações, 8 e 9 mai. 2014. Belo Horizonte, UFMG. p. 29-36.

CANDIDO, A. O direito à literatura. In: Vários Escritos. 3ed. São Paulo: Duas Cidades, 1995 
CARDOSO, B. SEPÚLVIDA, A. Entrar na cultura escrita pela porta da literatura infantil: reflexões a partir da pesquisa sobre a compreensão e os usos dos materiais educativos trilhas. In: Seminário Internacional Literatura na Educação Infantil: acervos, espaços e mediações, 8 e 9 mai. 2014. Belo Horizonte, UFMG. p. 81-104.

COELHO, Nely Novaes. Literatura: arte, conhecimento e vida. São Paulo: Petropólis, 2000.

HELD, J. O imaginário no poder: as crianças e a literatura fantástica. São Paulo: Summus, 1980.

HUZINGA, J. Homo Ludens: O jogo como elemento da cultura. São Paulo: Perspectiva, 1971.

MARTÍNEZ. M. B. S. Por qué icluir proyectos de lectura em educación inicial. In: Seminário Internacional Literatura na Educação Infantil: acervos, espaços e mediações, 8 e 9 mai. 2014. Belo Horizonte, UFMG. p.105-117.

OLIVEIRA, M. K. Vygostsky: aprendizado e desenvolvimento: um processo sóciohistórico. São Paulo: Scipione, 1997

VILLELA, B. Era uma vez um gato xadrez. São Paulo: Escala Educacional, 2003.

Balaio de Gatos: A formação leitora de crianças de 2 e 3 anos

\section{A AUTORA}

Alessandra Izabel dos Santos Lourenço é pedagoga, pós-graduada em Psicopedagogia Clínica e Institucional e mestranda em Linguística Aplicada na Universidade de Taubaté - UNITAU. É professora da carreira do Ensino Básico, Técnico e Tecnológico, atuando há 12 anos na Educação Infantil, na Escola Casimiro Montenegro Filho, no Departamento de Ciências e Tecnologia da Aeronáutica-DCTA, em São José dos Campos-SP.

E-mail: alessandra_isa35@hotmail.com 